\title{
Pelatihan Animasi Rangkaian Listrik Menggunakan Live Wire 1.11 Pro Bagi Siswa Kelas XII IPA 2 SMA Negeri 7 Mataram
}

\author{
Wahyudi*, Muh. Makhrus, I Wayan Gunada, Muhammad Taufik \\ Program Studi Pendidikan Fisika FKIP \\ Universitas Mataram, Kota Mataram, Indonesia
}

Kata Kunci:

Rangkaian

listrik, Media

animasi,

Livewire 1.11

pro

\begin{abstract}
Abstrak: Salah satu masalah di dunia pendidikan adalah rendahnya kemampuan siswa SMA dalam memecahkan soal-soal Fisika, terutama materi rangkaian listrik. Untuk mengatasinya, siswa perlu menggunakan media animasi sebagai alat bantu belajar, yang diharapkan dapat meningkatkan hasil belajar yang dicapainya. Salah satu media animasi adalah Livewire 1.11 pro, sebuah program komputer yang cukup membantu karena terdapat tampilan alur atau arah arus mengalir, sehingga mempermudah mindset pengguna akan jalannya arus dalam rangkaian listrik. Tujuan dari kegiatan pengabdian ini adalah melatih siswa-siswa untuk membuat animasi rangkaian listrik menggunakan Livewire 1.11 pro. Metode yang digunakan adalah metode ceramah dan tutorial cara menggunakan program komputer Livewire 1.11 pro, disertai contoh. Luaran yang diharapkan dalam kegiatan ini adalah siswa-siswa SMA memiliki kemampuan untuk membuat animasi rangkaian listrik menggunakan Livewire 1.11 pro.Setelah mengikuti kegiatan ini, siswa-siswa SMA memperolah tambahan wawasan pengetahuan dan keterampilan penggunaan program komputer Livewire 1.11 pro untuk mempermudah mempelajari rangkaian listrik.
\end{abstract}

Korespondensi: wahyudi_arsi@unram.ac.id

\section{PENDAHULUAN}

Fisika adalah ilmu yang mempelajari hukum-hukum yang menentukan struktur alam semesta dengan mengacu pada materi dan energi yang dikandungnya (Isaacs A, 1995). Fisika adalah cabang sains paling dasar, yang mempelajari perilaku dan struktur materi (Giancoli, 2014). Secara tradisional, Fisika dibagi menjadi beberapa bidang yang terpisah: kalor, cahaya, bunyi, listrik dan magnet, dan mekanika. Namun sejak awal abad ini, mekanika kuantum dan mekanika relativitas telah menjadi semakin penting. Pertumbuhan fisika modern diikuti oleh fisika atom, fisika inti dan fisika partikel. Fisika benda-benda astronomi dan interaksinya disebut astrofisika, fisika bumi disebut geofisika, dan ilmu yang mempelajari aspek fisika dari biologi disebut biofisika.

Untuk mempelajari ilmu fisika, yang diimplemetasikan dalam proses belajarmengajar, guru harus memiliki strategi, agar peserta didik dapat belajar secara efektif dan efisien, mengena pada tujuan yang diharapkan (Roestiyah, 2001). Salah satu langkah untuk memiliki strategi itu ialah harus menguasai teknik-teknik penyajian, atau biasanya disebut metode mengajar.

Selain itu, diperlukan media yang berfungsi sebagai alat bantu mengajar, berkembang sedemikian pesatnya sesuai dengan kemajuan sains dan teknologi. Ragam dan jenis media pun cukup banyak sehingga dapat dimanfaatkan sesuai dengan kondisi, waktu, keuangan, maupun materi yang akan disampaikan. Salah satu media yang digunakan dalam bahan ajar 
fisika adalah media animasi, yaitu sejenis multimedia yang memberikan kesempatan untuk belajar secara dinamis, interaktif dan perorangan. Dengan animasi, lingkungan pekerjaan yang kompleks dapat ditata sehingga menyerupai dunia nyata (Arsyad, 2009).

Berdasarkan dari hasil observasi di lapangan, ternyata sebagian besar siswa-siswa SMA mengalami kesulitan dalam mempelajari illmu Fisika. Hal ini dibuktikan dari hasil ujian nasional (UN) tingkat SMA se Nusa Tenggara Barat tahun 2018 diperoleh nilai ratarata mata pelajaran Fisika adalah 37,79 (Dinas Pendidikan dan Kebudayaan NTB). Salah satu pokok bahasan Fisika yang belum dikuasi oleh siswa-siswa SMA adalah rangkaian listrik, terutama mengenai hukum Ohm dan Kirchhoff (Ani Rusilawati, 2006). Untuk itu diperlukan terobosan agar siswa lebih mudah dalam mempelajari Fisika, terutama sub pokok bahasan rangkaian listrik yaitu dengan menggunakan media animasi, sebagai alat bantu mengajar. Penggunaan media animasi ini ternyata mampu meningkatkan hasil belajar maupun motivasi siswa dalam pembelajaran materi rangkaian (Sukiasa, Sukoco, 2013).

Salah satu animasi yang cukup mudah dibuat adalah Livewire 1.11. Program komputer Livewire 1.11 adalah suatu program yang merupakan suatu simulasi elektronika yang digunakan untuk merancang hingga menganalisis, ditampilkan dalam bentuk animasi dan dapat mengeluarkan bunyi untuk mempertunjukan fungsi atau prinsip dasar dari rangkaian listrik (Ramdhani M., 2013). Masih menurut Ramdhani M., Program Livewire salah satu jenis perangkat lunak aplikasi yang merupakan suatu subkelas perangkat lunak komputer yang memanfaatkan kemampuan komputer langsung untuk melakukan suatu tugas yang diinginkan pengguna. Walupun secara fiture program ini kalah jauh dengan program simulator yang lain dari segi data base komponennya, namun program simulator ini cukup membantu karena terdapat tampilan alur atau arah arus mengalir. sehingga mempermudah mindset kita akan jalannya arus dalam komponen.

Berdasarkan latar belakang di atas, maka perlu adanya suatu usaha agar siswa-siswa memiliki kemampuan dalam pembuatan animasi Livewire 1.11 Pro sebagai alat bantu untuk mempelajari pokok bahasan rangkaian listrik, yaitu melalui kegiatan: Pelatihan Pembuatan Animasi Rangkaian Listrik Menggunakan Livewire 1.11 Pro bagi Siswa Kelas XII IPA 2 SMA Negeri 7 Mataram.

Adapun tujuan dari kegiatan pengabdian ini adalah sebagai berikut:

1. Melatih siswa-siswa SMA 7 Negeri Mataram Kelas XII IPA 2 dalam pembuatan animasi rangkaian listrik dengan menggunakan Livewire 1.11 pro.

Sedangkan manfaat dari kegiatan pengabdian ini adalah sebagai berikut.

a. Meningkatkan minat siswa dalam pembuatan pembuatan animasi rangkaian listrik dengan menggunakan Livewire 1.11 pro.

b. Meningkatkan hasil belajar siswa khususnya dalam pokok bahasan rangkaian listrik.

Masalah yang terjadi di Pengabdian Masyarakat ini adalah kemampuan siswa-siswa dalam memecahkan soal-soal Fisika masih tergolong rendah, terutama pada pokok bahasan rangkaian listrik. Untuk itu diperlukan langkah-langkah yang mudah dan tepat dalam penyelesaian masalah ini, yakni dengan menggunakan media animasi Livewire 1.11 pro. Livewire 1.11 pro adalah suatu program komputer yang berupa simulasi elektronika yang digunakan untuk merancang hingga menganalisis, ditampilkan dalam bentuk animasi dan 
dapat mengeluarkan bunyi untuk mempertunjukan fungsi atau prinsip dasar dari rangkaian listrik, sehingga lingkungan pekerjaan yang kompleks dapat ditata menyerupai dunia nyata. Dengan demikian, diharapkan hasil belajar siswa akan lebih baik.

Berdasarkan masalah yang dialami oleh para siswa, maka usaha yang dilakukan untuk memecahkan masalah tersebut adalah dengan memberikan kegiatan pelatihan dengan metode ceramah dan tutorial cara membuat animasi rangkaian listrik menggunakan program komputer Livewire 1.11 pro, disertai contoh-contoh. Target luaran yang diharapkan dalam kegiatan ini adalah siswa-siswa SMA Negeri 7 Mataram kelas X IPA memiliki kemampuan untuk membuat animasi rangkaian listrik menggunakan Livewire 1.11 pro. Dengan demikian hasil belajar siswa diharapkan meningkat.

\section{METODE KEGIATAN}

Pengabdian Masyarakat ini dilaksanakan dalam bentuk pelatihan yang terdiri dari dua tahap yaitu: tahap pertama, pelatihan pemantapan pemahaman desain pembuatan animasi Livewire1.11 pro secara teoritis dan tahap kedua, ceramah/diskusi tentang praktek pembuatan rangkaian listrik menggunakan media Livewirel.11 pro.

Kegiatan pengabdian pada masyarakat ini secara efektif di dilakukan selama 8 bulan terhitung dari tanggal April sampai dengan September 2019.

\section{Rancangan Evaluasi}

Tujuan dari evaluasi adalah memanfaatkan informasi yang diperoleh sebagai acuan dalam menentukan perlakuan selanjutnya. Evaluasi direncanakan dilakukan diakhir kegiatan dengan cara meminta kepada para peserta untuk mengungkapkan kesan dan pesan yang dirasakan setelah mengikuti kegiatan penyuluhan dan meminta peserta untuk memberi saransaran dalam rangka kegiatan yang akan datang. Keberhasilan kegiatan ini dapat dilihat dari banyak sedikitnya aspek positif dan aspek negatif yang dikemukakan oleh peserta.

\section{HASIL DAN PEMBAHASAN}

Pelaksanaan kegiatan pelatihan pembuatan animasi rangkaian listrik dengan menggunakan program komputer LiveWire 1.11 pro kepada siswa-siswi SMA Negeri 7 Mataram kelas XII IPA 2 diaksanakan pada hari Rabu, 28 Agustus 2019. Pelatihan penggunaan program komputer LiveWire 1.11 pro diikuti oleh 32 siswa-siswi SMA Negeri 7 Mataram kelas XII IPA 2 . Berikut ini adalah tabel peserta kegiatan pengabdian.

Berdasarkan hasil pengamatan, tanya jawab, dan wawancara kepada beberapa peserta pelatihan secara acak diperoleh data bahwa kegiatan ini sangat bermanfaat bagi para peserta untuk memahami dan mempermudah mempelajari rangkaian listrik, terutama pada sub pokok bahasan hukum Ohm dan Kirchhoff. Hukum ini secara perumusan matematik adalah sederhana, karena mudah diingat, namun dalam tahap implementasinya, yaitu dalam bentuk menyelesaian soal sebagian besar siswa mengalami kesulitan. Sehingga tidak mengherankan bila sub pokok bahasan hukum Ohm dan Kirchhoff tersebut menjadi salah satu materi di SMA yang belum dikuasainya (Ani Rusilawati, 2006). 
Table 1. Nama Peserta Kegiatan Pelatihan

\begin{tabular}{|c|l|c|l|}
\hline No & \multicolumn{1}{|c|}{ Nama Peserta } & No & \multicolumn{1}{|c|}{ Nama Peserta } \\
\hline 1 & Rohana & 17 & Jayadi Alfian Ramadhan \\
\hline 2 & Ardhia Pramesti Regita Cahyani & 18 & Aulia Rochullah Adis Akbar \\
\hline 3 & Elda Nur Atika & 19 & Muhammad Zidu Al Rasyid \\
\hline 4 & Tari Andriani & 20 & Edwin Hidayanurrahman Saputra \\
\hline 5 & Okta Aliffia & 21 & Kuriawan Hidayat \\
\hline 6 & Samsul Indrawan & 22 & Maulana Amri \\
\hline 7 & M. Tamrin & 23 & Lalu Marta Hidayat Barma \\
\hline 8 & M. Zillurahman & 24 & M. RafliDika Wardana \\
\hline 9 & Andy Ayu Sabila & 25 & Muh. Aris Ahyan \\
\hline 10 & G. B. Naufal Adifa Suharta & 26 & Claudia Sukmawati \\
\hline 11 & Alfina Laila Mayunika & 27 & Nahia Ahista \\
\hline 12 & Arika Rizky Sari & 28 & Puji Sri Wahyuningsih \\
\hline 13 & Nining Firdaus Amaryana & 29 & Salsabila Restu Refriaananda \\
\hline 14 & Putri Karinda & 30 & Alya Fadiyah Yasmin \\
\hline 15 & Wanni Sefiana & 31 & Dara Intan Ariati Cantik \\
\hline 16 & Khairil Kahfi & 32 & Najwa Fauzi Harharah \\
\hline
\end{tabular}

Beberapa penyebab siswa mengalami kesulitan dalam mempelajari hukum Ohm dan Kirchhoff karena sub pokok bahasan tersebut bersifat abstrak, dan menggunakan operasi penjumlahan secara aljabar, yaitu operasi penjumlahan yang bisa berupa penjumlahan atau pengurangan bergantung pada perjanjian tanda. Dengan menggunakan program komputer LiveWire 1.11 pro, akan membantu siswa-siswi melihat secara visual perjalanan dan arah arus listrik yang melewati penghantar dan beberapa komponen yang lainnya. Selain itu program komputer LiveWire 1.11 pro bisa digunakan sebagai kunci jawaban, untuk membuktikan apakah penyelesaian soal yang telah dikerjakannya sudah benar atau belum.

Para peserta berharap agar kegiatan pengabdian seperti ini dapat dilakukan secara rutin dengan materi yang berbeda, terutama tentang animasi beberapa materi fisika yang besifat abstrak. Dengan demikian, ilmu fisika tidak hanya bersifat matematis belaka, akan tetapi bisa divisualkan sehingga dapat mengubah pola pikir siswa, bahwa fisika adalah salah satu pelajaran yang sulit dan tidak menarik akan dapat diatasi.

Berikut ini disajikan tabel pemateri dan materi yang diberikan Tim Pengabdian kepada siswa-siswi SMA Negeri 7 Mataram, sebagai peserta kegiatan.

\begin{tabular}{|l|l|l|}
\hline No & \multicolumn{1}{|c|}{ Pemateri } & \multicolumn{1}{c|}{ Judul } \\
\hline 1 & I Wayan Gunada, S.Si., M.Pd & Media pembelajaran Animasi \\
\hline 2 & $\begin{array}{l}\text { Muhammad Taufik, S.Pd., } \\
\text { M.Si }\end{array}$ & $\begin{array}{l}\text { Penyelesaian hukum Kerchhoff dengan menggunakan } \\
\text { matrik }\end{array}$ \\
\hline 3 & Dr. Muh. Makhrus, M.Pd & Pengantar program Live Wire 1.11 pro \\
\hline 4 & Wahyudi, M.Si & Penerapan program komputer Live Wire 1.11 pro \\
\hline
\end{tabular}


Adapun beberapa dokumentasi kegiatan pengabdian adalah sebagai berikut:

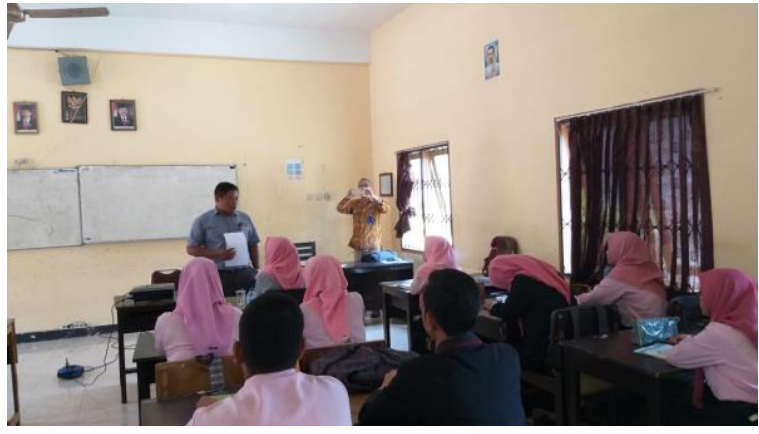

Gambar 1a. Penyampaian materi oleh I Wayan Gunada, S.Si., M.Pd

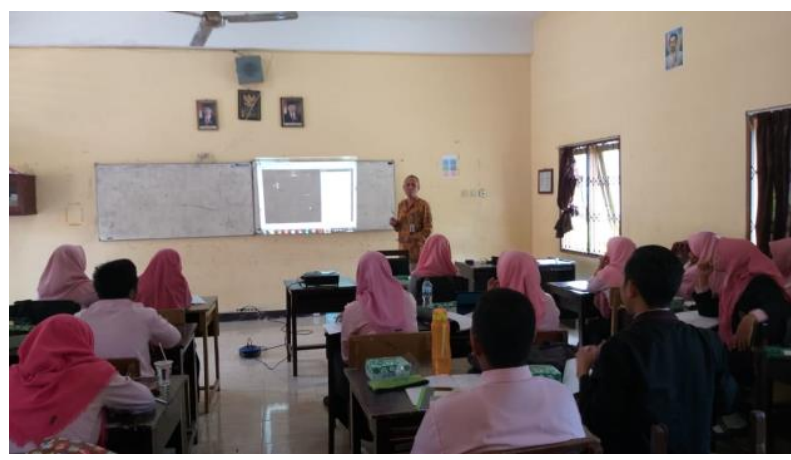

Gambar 1c. Penyampai materi oleh Wahyudi

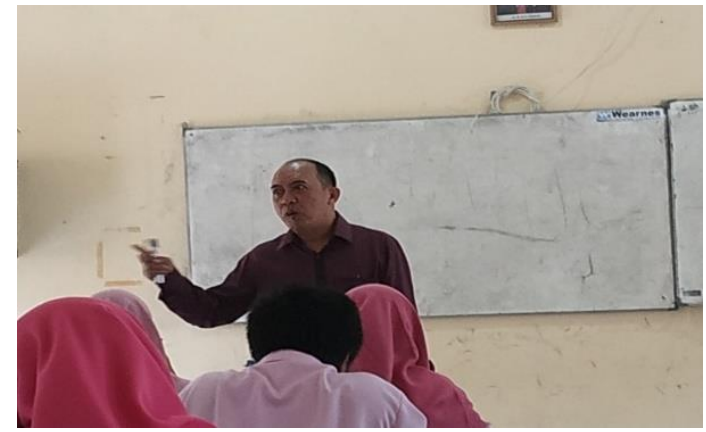

Gambar 1b. Penyampaian materi oleh Muhammad Taufik, S.Pd., M.Si

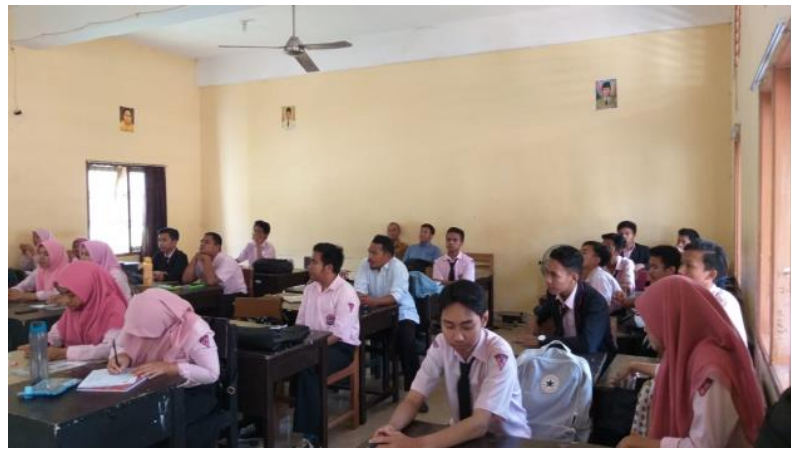

Gambar 1d. Antusias Peserta

\section{KESIMPULAN DAN SARAN}

Berdasarkan hasil observasi selama kegiatan berlangsung, termasuk tanya jawab, diperoleh informasi sebagai berikut:

1. Materi yang disampaikan dalam kegiatan pengabdian ini sangat menarik, karena terdapat hal baru dalam mempelajari rangkaian listrik, yaitu dalam bentuk animasi LiveWire 1.11 pro, sehingga menjadi lebih mudah, efektif dan efisien. Karena itu peserta mengusulkan kegiatan pengabdian seperti ini sebaiknya dijadikan kegiatan rutin dengan materi yang berbeda dan durasi waktu yang lebih lama.

2. Peserta sangat senang dan tertarik dengan kegiatan pengabdian ini.

3. Kegiatan ini memberikan manfaat dan inspirasi peserta untuk mengembangkan pembuatan animasi rangkaian listrik

\section{Ucapan Terima Kasih}

Penulis mengucapkan terima kasih kepada DIPA BLU Universitas Mataram yang telah memberi dukungan finansial terhadap pengabdian ini.

\section{DAFTAR PUSTAKA}

Arsyad, Azhar. 2009. Media Pembelajaran, Jakarta: Rajawai Pers.

Giancoli D. C., 2014, Fisika: Prinsip dan Aplikasi, Jakarta: Penerbit Erlangga 
Isaacs A, 1995, Kamus Lengkao Fisika, Jakarta: Penerbit Erlangga

Kusnadi, C., dan Sutjipto B., 2013, Media Pembelajaran; Manual dan Digital, Jakarta: Penerbit Ghalia Indonesia.

Roestiyah, 2001, Strategi Belajar Mengajar, Jakarta: Penerbit Rineka Cipta

Rusilowati, A, 2006. Profil Kesulitan Belajar Fisika Pokok Bahasan Kelistrkan Siswa SMA di kota Semarang, Jurnal Pendidikan Fisika Indonesia, Vol. 4 Nomor 2, https://journal.unnes.ac.id/.

Sukiasa K., dan Sukoco, 2013. Pengaruh Media Animasi terhadap Hasil Belajar Siswa Materi Sistem Kelistrikan Otomotif, Jurnal Pendidikan Vokasi, Vol. 3 Nomor 1, https://journal.uny.ac.id >

Ramdhani, M. 2013. Tutorial Livewire 1.1 Pro. www.academia.edu diakses tanggal 12 Februari 2019. 